\title{
No temporal association between influenza outbreaks and invasive pneumococcal infections
}

\author{
Andre Michael Toschke, ${ }^{1,2}$ Stephan Arenz, ${ }^{1}$ Rüdiger von Kries, ${ }^{1}$ Wolfram Puppe, ${ }^{3}$ \\ Josef A I Weigl, ${ }^{3}$ Michael Höhle, ${ }^{4}$ Ulrich Heininger ${ }^{5}$
}

${ }^{1}$ Institute for Social Pediatrics and Adolescent Medicine, Ludwig-Maximilians University Munich, Munich, Germany:

${ }^{2}$ Division of Health and Social Care Research, King's College London, London, UK; ${ }^{3}$ Pediatric Infectious Diseases, University Children's Hospital Kiel, Kiel, Germany; ${ }^{4}$ Department of

Statistics, Ludwig-Maximilians University Munich, Munich, Germany; ${ }^{5}$ Division of Pediatric Infectious Diseases, University Children's Hospital Basel, Basel, Switzerland

Correspondence to:

Professor Ulrich Heininger,

University Children's Hospital

Basel, PO Box 4005, Basel,

Switzerland;

Ulrich.Heininger@unibas.ch

Accepted 19 March 2007

Published Online First

12 April 2007

\section{ABSTRACT}

Objective: To assess whether the influenza peak in populations precedes the annual peak for invasive pneumococcal infections (IPI) in winter.

Design: Ecological study. Active surveillance data on influenza $A$ and $I P I$ in children up to 16 years of age collected from 1997 to 2003 were analysed.

Setting: Paediatric hospitals in Germany.

Patients: Children under 16 years of age.

Results: In all years under study, the influenza A season did not appear to affect the IPI season $(p=0.49)$. Specifically, the influenza peak never preceded the IPI peak.

Conclusion: On a population level there was no indication that the annual influenza epidemic triggered the winter increase in the IPI rate or the peak of the IPI distribution in children

A number of animal studies have shown that preceding influenza infection increased the lethality of invasive pneumococcal infections (IPI)..$^{1-3}$ In a French study, $12 \%$ of cases of community acquired pneumonia in children were presumed to be causally linked to preceding influenza infections. ${ }^{4}$ Further, a small case-control study in hospitalised children showed a significant association between severe pneumococcal pneumonia and preceding influenza. ${ }^{5}$

In this study we took advantage of established active national surveillance systems and compared the time course of IPI in children $0-16$ years of age over a period of 7 years with the timing of influenza $\mathrm{A}$ infections in the respective years and age group in order to assess whether influenza $A$ is associated with an increase in IPI.

\section{METHODS}

In this ecological study, IPI cases were reported by an active hospital-based surveillance system in the German population up to 16 years of age from January 1997 to June 2003. ${ }^{6}$ Patients were enrolled if they had been admitted to a paediatric hospital and if Streptococcus pneumoniae had been isolated from at least one culture of blood, CSF or a sample from any other normally sterile body site. Patients with otitis media were not included. Cases were reported by paediatric hospitals on a monthly basis by means of postcards. Reports were validated by subsequent questionnaires.

The Pediatric Infectious Diseases Network on Acute Respiratory Tract Infections (PID-ARI.net) has registered cases of influenza $A$ in children under the age of 16 years in a sentinel surveillance system comprising two (northern and central regions of Germany up to June 2002) and three (northern, central and southern regions of Germany since July 2002) areas of Germany. Patients have been recruited from three university children's hospitals, three municipal children's hospitals and eight private paediatric practices.' This surveillance system covers about 500000 children per region (2\% of the total German population). Naso-pharyngeal aspirates of children with acute respiratory infections were sent to the laboratory of the university children's hospital in Kiel and were analysed by multiplex RT-PCRELISA. ${ }^{8}$

\section{Statistical analysis}

The seasonal distributions of IPI and influenza A cases observed from January 1997 to June 2003 were separately analysed with the R package "surveillance". ${ }^{10}$ The algorithm by Farrington et al was used to identify possible outbreaks in the two time series. ${ }^{11}$ The random error level for outbreak identification was set to $\alpha<0.001$. Three previous years with a 2 -month time period were considered for definition of sensible thresholds enabling analysis from 2000 onwards with the original Farrington algorithm. ${ }^{11}$ Additional analyses for the years 1998 and 1999 considered only one previous year for threshold definition. Zero counts of influenza data were replaced by 0.1 to ensure convergence of the generalised model algorithm. Both time series were compared with respect to identified outbreaks. Additional multivariate time series analysis to assess a possible association between influenza and pneumococcal infections with time lag 1 was performed using the " $3 \mathrm{~h}$ algorithm". The $3 \mathrm{~h}$ algorithm is based on a multivariate branching process with immigration and also implemented in the "surveillance" package. $^{12}$

All calculations were carried out with the statistical software package $\mathrm{R}$ version 2.4.0. ${ }^{13}$

\section{RESULTS}

Between January 1997 and June 2003, a total of 1474 cases of IPI were reported in children 0-16 years of age in Germany. Throughout the study period, the highest proportion of cases was observed between October and May (fig 1). In the corresponding same time period, 737 cases of influenza A were reported. Most of the cases occurred between January and April. As can be seen in fig 1, in each study year the increase in IPI preceded the onset of the influenza season by several months. One outbreak could be identified for the influenza time series by the Farrington algorithm in 2003 (fig 2), whereas no 


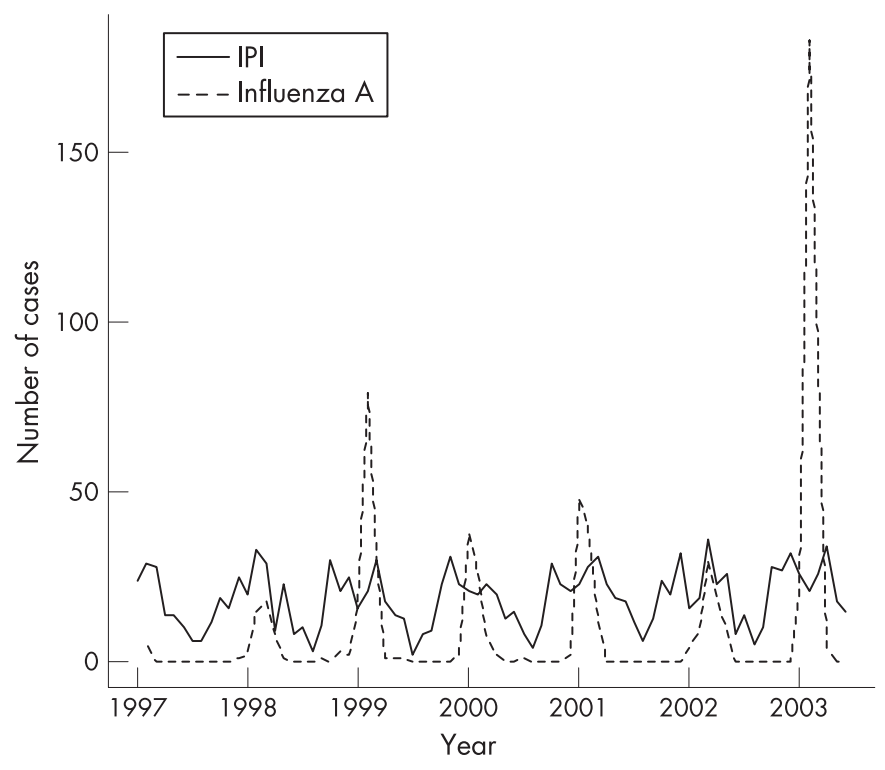

Figure 1 Time course of children hospitalised for IPI in Germany and of children with influenza A between January 1997 and June 2003.

IPI outbreak was identified during the entire observation period (data not shown). However, the influenza outbreak in 2003 was not followed by an outbreak of IPI.

Additional analyses considering only one previous year for defining alarm thresholds identified another influenza outbreak in 1999 (data not shown). Again, this outbreak was not followed by a significant increase in IPI. Furthermore, multivariate analysis of both time series by the $3 \mathrm{~h}$ algorithm did not show an association between influenza and pneumococcal infections with a time lag of 1 month $(p=0.49)$ : the incidence of IPI was independent of the influenza season or outbreaks and did not rise after the onset of any influenza season.

Also, the absence of a sequential association between the onset of the influenza season and an increase in cases of IPI was not related to the type of IPI, that is, the time course of bacteraemic pneumococcal pneumonia was similar to that of all IPI (data not shown).

\section{DISCUSSION}

In contrast to experimental studies in animals, which postulated an excess mortality due to pneumococcal infections following influenza, no temporal association between the time course of IPI in children and influenza A was found in our ecological study. ${ }^{1-3} 14$ The irregularly occurring influenza B seasons (seasons 1998/99, 2001/02 and 2002/2003) ${ }^{7}$ coincided with the referring influenza A seasons (data not shown).

The lack of an association is unlikely to be explained by differences in age, as influenza has clearly been shown to occur in significant numbers in children $<5$ years of age (mean age 2.5-3.5 years), ${ }^{15}$ which is the main age group also affected by IPI, in Germany and elsewhere. ${ }^{15-17}$

Our observation is in contrast with the results of a small casecontrol study comprising 13 children with severe pneumococcal pneumonia. In that study, patients more frequently experienced an influenza-like illness in the preceding weeks than did controls. ${ }^{4}$ However, a laboratory proven sequence of influenza followed by pneumococcal pneumonia was present in only five cases, which is an important limitation. However, the existence of an association is supported by several animal studies showing a lethal synergism between influenza and pneumococcal

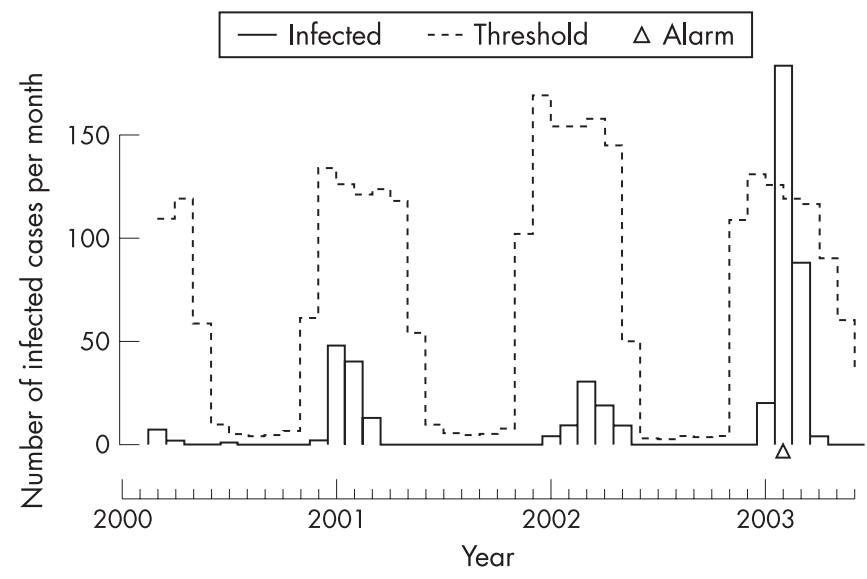

Figure 2 Results of the algorithm by Farrington et al ${ }^{11}$ for the influenza time series.

infections, suggesting that influenza infection paves the way for a more severe course of IPI..$^{1-3}$ Therefore, it was tempting for us to assume that the onset of the influenza season would be followed by an increase in IPI rates. We tested our data for possible outbreaks of influenza and IPI using the method described by Farrington et al. ${ }^{11}$ The $\mathrm{R}$ package statistical computing system allowed us to fit these models based on weekly observations. However, there was no evidence for such a sequential association. Although we cannot exclude that IPI might have been triggered by preceding influenza in some individual children, there was no indication for a significant association at the population level. In agreement with our findings, a recent study from Australia examined the relationship between virus activity, climatic parameters and IPI during a winter in which there were separate peak incidences of influenza and respiratory syncytial virus (RSV) infection. In children, RSV activity was significantly positively correlated with IPI activity but influenza virus activity was not. ${ }^{18}$

Further, we can not exclude that non-invasive pneumococcal infections may be triggered by influenza or other viral respiratory pathogens and our findings by no means should discourage immunisation of children against influenza and IPI according to current national recommendations.

\section{What is already known on this topic}

- In animals, preceding influenza infection increased the lethality of invasive pneumococcal infections.

- Community acquired pneumonia in children has been presumed to be causally linked to preceding influenza infections.

\section{What this study adds}

- Data from an active hospital-based surveillance system for invasive pneumococcal infections and a sentinel surveillance system for influenza A infections in children under the age of 16 years in Germany were analysed.

- No temporal association between the time course of invasive pneumococcal infections in children and influenza A was found. 
Funding: The surveillance of invasive pneumococcal infections in children in Germany was supported by Wyeth Pharma Germany, Münster and by a grant (FKZ 01KI0213) for PID-ARI.net (Pediatric Infectious Diseases Network on Acute Respiratory Tract Infections) awarded by the Bundesministerium für Forschung (BMBF).

Competing interests: Rüdiger von Kries is conducting a surveillance study on invasive pneumococcal infections in children in Germany funded by the manufacturer of a 7-valent pneumococcal vaccine, Prevenar (Wyeth) and - on a few occasions has accepted honoraria for lectures given at meetings sponsored by Wyeth. Ulrich Heininger is a member of the Prevenar Advisory Board of Wyeth/Switzerland.

\section{REFERENCES}

1. McCullers JA, Bartmess KC. Role of neuraminidase in lethal synergism between influenza virus and Streptococcus pneumoniae. J Infect Dis 2003;187:1000-9.

2. McCullers JA, Rehg JE. Lethal synergism between influenza virus and Streptococcus pneumoniae: characterization of a mouse model and the role of platelet-activating factor receptor. J Infect Dis 2002;186:341-50.

3. van der Sluijs KF, van Elden LJ, Nijhuis M, et al. IL-10 is an important mediator of the enhanced susceptibility to pneumococcal pneumonia after influenza infection. J Immunol 2004;172:7603-9.

4. Pons-Catalano C, Vallet $\mathrm{C}$, Lorrot $\mathrm{M}$, et al. Community acquired pneumonia and influenza in children. Arch Pediatr 2003;10:1056-60.

5. O'Brien KL, Walters MI, Sellman J, et al. Severe pneumococcal pneumonia in previously healthy children: the role of preceding influenza infection. Clin Infect Dis 2000:30:784-9.

6. von Kries R, Siedler A, Schmitt HJ, et al. Proportion of invasive pneumococcal infections in German children preventable by pneumococcal conjugate vaccines. Clin Infect Dis 2000;31:482-7.
7. PID-ARI.net. Pediatric Infectious Diseases Network on Acute Respiratory Tract Infections. Available at http://www.pid-ari.net (accessed 21 October 2007).

8. Gröndahl B, Puppe W, Hoppe A, et al. Rapid identification of nine microorganisms causing acute respiratory tract infections by single-tube multiplex reverse transcription-PCR: feasibility study. J Clin Microbiol 1999;37:1-7.

9. Puppe W, Weigl JA, Aron G, et al. Evaluation of a multiplex reverse transcriptase PCR ELISA for the detection of nine respiratory tract pathogens. J Clin Virol 2004;30:165-74.

10. Höhle M. An R-package for the surveillance of infectious diseases. In: Rizzi A, Vichi M, eds. Proceedings in Computational Statistics, 17th Symposium. 28 August-1 September 2006, Rome, Italy. Heidelberg: Physica-Verlag, 2006:1327-34.

11. Farrington $\mathbf{C P}$, Andrews NJ, Beale $A D$, et al. A statistical algorithm for the early detection of outbreaks of infectious disease. J R Statist Soc A 1996;159:547-63.

12. Held L, Höhle M, Hofmann M. A statistical framework for the analysis of multivariate infectious disease surveillance counts. Statistical Modelling 2005;5:187-99.

13. R Development Core Team. R: a language and environment for statistical computing. Vienna, Austria: R Foundation for Statistical Computing, 2006 (http:// www.R-project.org).

14. Peltola VT, McCullers JA. Respiratory viruses predisposing to bacterial infections: role of neuraminidase. Pediatr Infect Dis J 2004;23:S87-97.

15. Weigl JA, Puppe W, Schmitt HJ. The incidence of influenza-associated hospitalizations in children in Germany. Epidemiol Infect 2002;129:525-33.

16. Glezen WP. Emerging infections: pandemic influenza. Epidemiol Rev 1996;18:64-76.

17. Izurieta HS, Thompson WW, Kramarz P, et al. Influenza and the rates of hospitalization for respiratory disease among infants and young children. N Engl J Med 2000;342:232-9.

18. Watson M, Gilmour R, Menzies R, et al. The association of respiratory viruses, temperature, and other climatic parameters with the incidence of invasive pneumococcal disease in Sydney, Australia. Clin Infect Dis 2006;42:211-15.

\section{Dreamflight 2008: request for nominations}

Established in 1986, Dreamflight is a registered UK charity that takes disabled and seriously ill children to the theme parks of central Florida. The charity charters a Boeing 747 and takes 192 children aged 8-14 years from the UK whose illnesses and circumstances have made their lives difficult. The children are supported by a team of volunteers including paediatricians, paediatric nurses and physiotherapists, so that as long as they are able to be away from home for 10 days, no matter what the underlying condition is they are able to experience a holiday of a lifetime in safety.

We are now inviting nominations from professionals for Dreamflight 2008 (18-28 0ctober). If your team cares for a child who may benefit from this experience and you would like to request a nomination form, or to find out more about the work of Dreamflight, please contact:

Website: www.Dreamflight.org

Email: Office@Dreamflight.org

Tel: $+44(0) 1494722733$ 

outbreaks and invasive pneumococcal infections

Andre Michael Toschke, Stephan Arenz, Rüdiger von Kries, et al.

Arch Dis Child 2008 93: 218-220 originally published online April 3, 2007

doi: 10.1136/adc.2006.098996

Updated information and services can be found at:

http://adc.bmj.com/content/93/3/218.full.html

\section{These include:}

References This article cites 15 articles, 9 of which can be accessed free at: http://adc.bmj.com/content/93/3/218.full.html\#ref-list-1

Article cited in:

http://adc.bmj.com/content/93/3/218.full.html\#related-urls

Email alerting Receive free email alerts when new articles cite this article. Sign up in service the box at the top right corner of the online article.

$\begin{array}{cc}\text { Topic } & \text { Articles on similar topics can be found in the following collections } \\ \text { Collections } & \text { Influenza (36 articles) } \\ \text { TB and other respiratory infections (368 articles) } \\ \text { Child health (2034 articles) } \\ \text { Epidemiologic studies (930 articles) }\end{array}$

Notes

To request permissions go to:

http://group.bmj.com/group/rights-licensing/permissions

To order reprints go to:

http://journals.bmj.com/cgi/reprintform

To subscribe to BMJ go to:

http://group.bmj.com/subscribe/ 